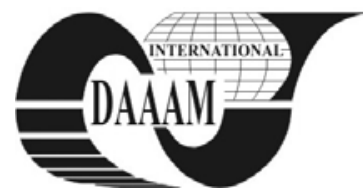

\title{
FRAMEWORK FOR AN INTEGRATED ONTOLOGY DEFINITION IN THE SCOPE OF CMM INSPECTION PLANNING USING CBR
}

\author{
BARREIRO, J[oaquin]; MARTINEZ PELLITERO, S[usana]; GONZALEZ MADRUGA, M[anuel]; \\ GONZALEZ - MADRUGA, D[aniel] \& GONZALEZ, J[avier]
}

\begin{abstract}
Case based reasoning (CBR) methodologies are one the nowadays methodologies for automating decision making. However, most of the implemented systems are related to fields far from manufacturing engineering. Also, most of the CBR systems use not standard lenguages and interfaces for knowledge representation. In this paper an ontology is presented for CBR knowledge representation in the scope of inspection planning with coordinate measuring machines. The ontology has been represented using a formal and widely accepted language, the express language, so the integration with other models in the product lifecycle is easier. The ontology serves as basis for development of inspection planning applications.
\end{abstract}

Key words: ontology, KBE, inspection, express

\section{INTRODUCTION}

Success in implementation of computer integrated manufacturing and concurrent engineering depends on the level of automation in planning of processes through computer applications (CAPP). However, few researching have focused on inspection process planning. In this paper, a research work is presented in the scope of operation planning, in particular in the scope of inspection processes. Case based reasoning (CBR) methodology is used, which is one of the nowadays knowledge technologies. CBR is applied to obtain significant improvements in the development of computer integrated subsystems (Ho \& Mathew, 2008).

In this context, although numerous works can be found in the scope of medical decision making, in the field of mechanical engineering are significantly few works. Some references worth to mentioning are the following.

Liu et al (Jia-Li et al., 2008) applyed CBR methodology to support mechanical design process. Che (Che \& Lin, 1998) proposed a system for supporting decision making based on the quality function deployment (QFD), but it gives support only to the product functionality, instead of providing advices to product design. Hongyue (Hongyue et al., 2001) proposed a system to support mechanical design of a product, but the system have not an efficient mechanism to acquire the knowledge. Ho (Ho \& Mathew, 2008) developed a system for supporting the design of forging processes using the protegé language.

\section{METHODOLOGY}

The most important process in a CBR system is the recovering of cases similar to the case to solve. All CBR applications execute a function of similarity, so that they apply values to certain parameters or attributes of the new case and introduce them in a predefined mathematical function. The result of evaluating this function is a match number related to the cases stored in the case database. The case that presents the highest similarity among these parameters will be chosen as the most similar case, and its solution will be applied to the new case, obviously adapting the solution as function of the new case parameters. Implementation of any CBR system requires defining limits where cases stored in the case database would be defined without ambiguity. The CBR application works on representations of specific tasks of problems already solved in the past, and they learn about how to solve a new problem. A CBR system is also a self-expandable system (the solution to the current problem is stored as a new case that can be recovered in future problems).

The methodology followed here is based on the reference to geometrical features of the part to inspect. Each feature to inspect is called an inspection feature, which may include pairs of part faces. Then, three steps are applied:

- Representation: the inspection features must be represented in such a way that they can be compared with the existing ones in the case database.

- Retrieval: inspection features similar to the actual ones should be retrieved from the case database. A procedure for classifying them is defined to simplify the search.

- Adaptation: once the ideal inspection feature is identified in the case database, the solution implied must be adapted to the actual case, modifying and evaluating the final result.

The new result is then stored in the case database to use in future interactions.

The ontology used in this research is partially founded in the work of Wong (Wong et al., 2006). The cases representation used by this author is redundant in extreme and the representation format is not standarized. This means that the integration with other models along the product lifecycle is very difficult or impossible. In this paper a modified ontology has been defined for improving the coherence, redundancy and consistence of the final model; besides, a standard and accepted language of representation is used. Also, the integration in concurrent frameworks based on STEP is pretended. For it, the knowledge is represented using the Express language. The Express language assures integrity with other models in the product lifecyle. This knowledge is stored in a central repository for using it in future applications or cases.

The main objective here is to give the infrastructure for development of automated planning systems in mechanical part inspection. Our work shows an ontology and a case representation scheme for the automatic planning of inspection processes. Basically, the scope of the work is the inspection of parts with prismatic, cylindrical or free-form inspection features. The methodology and solution provided is based on the use of CBR for CAIPP development in CIM environments.

\section{RESULTS AND DISCUSSION}

A framework ontology has been implemented using several resources and technologies. The CBR has been used as base methodology and the Express language as representation method. The ontology is structured as follows: the root concept is the "CMM Inspection Case Database", where all the past cases are registered. This database contains a set of "Inspection 
case records", each one associated with the way of inspectioning a inspection feature. So, each inspection case record references a "Inspection case", with contains knowledge about the inspection feature involved, the structure of the particular case and the relationships among the elements of this case structure. Each inspection feature is defined through a set of concepts: class of feature, part faces involved in the feature and set of boundary (Wong et al., 2006). The class of the feature defines the type as single, external, internal, free-form, offset. Each one of these classes collects different inspection geometries which can be found.

The "Structure of the case" is composed of a set of specifications, a set of conditions and a set of processes. The set of "Conditions" includes the conditions in which inspection was performed, such as temperature range, calibration state of the equipment, stabilization time, and so on. The set of "Specifications" includes tolerances and type of inspection operation, such as nominal size, tolerance interval, type of GD\&T tolerance, measurement in depth, and so on. The set of "Processes" includes the steps and resources employed in the inspection, such as positioning operations, part stabilization operations, configuration of inspection equipment used and its precision and resolution, datums and objective face, and operation sequence.

The relationships among the elements of the case structure define a spatial graph which provides consistency to the case. It is the base for future comparison when planning a new case. The relationships are define using "nodes" and "arcs".

Nodes represent the component elements of the inspection case, whereas arcs define the existing relationships between nodes and the value of this link. For example, the link between a datum (node 1) and the equipment used to measuring it (node 2 ); the value of the relationship will be the order of the datum in the datum list (datum 1). All these possible relationships are classified in several types. All these elements of the ontology have been formally represented using the Express language and its graphical variant, Express-G. As it is known, this language was defined as the base representation language in the STEP standard. Therefore, the Express representation will make easier the integration of this model with other information/knowledge models and ontologies defined through the full product development lifecycle. Figure 1 shows an extract of the developed model.

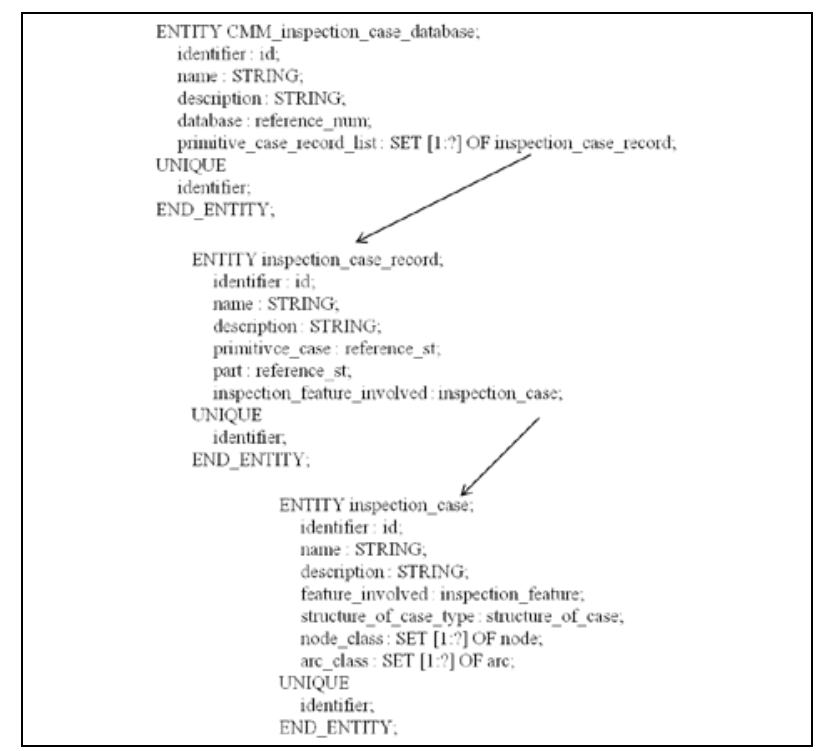

Fig. 1. An extract on the ontology in Express

The schema so defined was implemented in the Express Data Manager database. The Express Data Manager software is used as central repository (Figure 2): a database which stores information and rules in accordance to a predefined express schema. Then, knowledge stored in the case database is used to make easier the task of reasoning when defining a new inspection operation plan, that is, it acts as an important aid for inspection operators. The models proposed serve as basis for developing computer aided planning software.

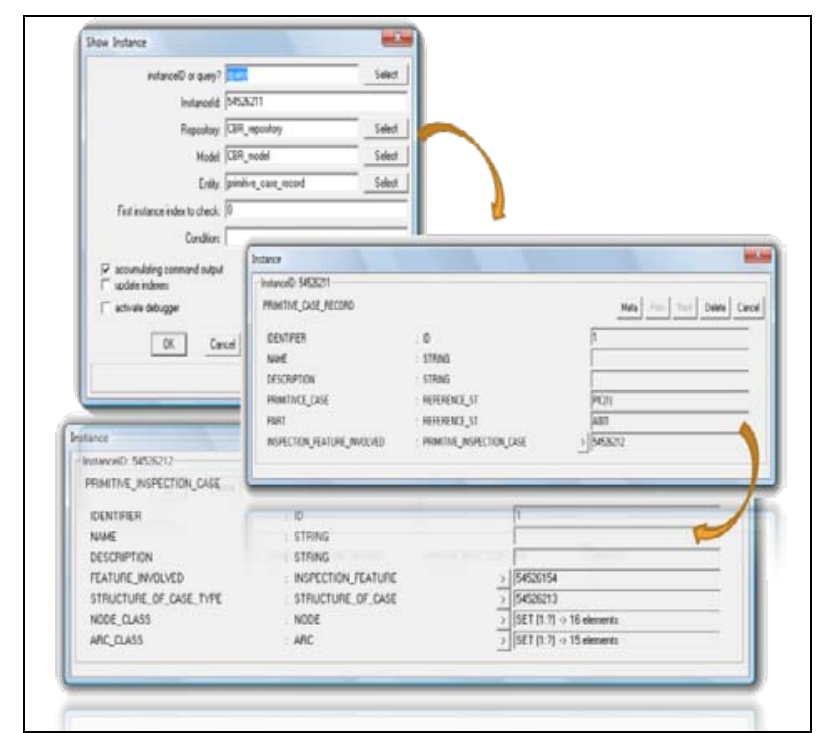

Fig. 2. Example of case database

\section{CONCLUSION}

A modified knowledge ontology has been defined for inspection planning with CMMs. The proposed system using the CBR opens a new era in the computer aided inspection planning research. The combination of CBR together with Express language assures the consistence and coherence of the information and knowledge with regard to other activities along the product development cycle. The methodology proposed for the inspection planning can be applied to other planning operations in the production.

\section{ACKNOWLEDGEMENTS}

We gratefully acknowledge the financial support provided by the Spanish Minister of Science and Innovation through project DPI2008-01974.

\section{REFERENCES}

Che, A. \& Lin, Z. (1998). A QFD-based decision support system for product development. China Europe Network for Integration in Manufacturing, 10 (1) (72-82)

Ho, C. \& Mathew, J. (2008). Case-Based Reasoning System for Forging Process Design. Proceed. 3rd Intl. Conf. Innovative Computing Information and Control, June 18-20, Dalian, Liaoning China, ISBN: 978-0-7695-3161-8, 7 (45)

Hongyue, D.; Yanming, S. \& Shixiong, Z. (2001). Research on intelligent decision support system for mechanical products design. Machinery Manufacturing Engineer, 11 (31-33)

Jia-li, L.; Xiang-bin, Y.; Wei, Q. \& Yi-jun, L. (2008). A casebased reasoning system for mechanical design. Proceed. 15th Intl. Conf. Management on Science and Engineering, September 10-12, Long Beach, USA, ISBN: 978-1-42442387-3, 585-590

Wong, F.S.Y.; Chuah, K.B. \& Venuvinod, P.K. (2006). Automated inspection process planning: Algorithmic inspection feature recognition and inspection case representation for CBR. Robotics and Computer-Integrated Manufacturing, 22 (56-68) 